\title{
An Unusual Diagnosis in a Patient with Chest Pain and Decreased Left Upper Extremity Blood Pressure
}

\section{(1) Kıvanç Karaman, (1) Kübra Șahin}

Department of Emergency Medicine, Süleyman Demirel University Faculty of Medicine, Isparta, Turkey

A 69-year-old male patient was admitted to the emergency department of a rural hospital with left arm and chest pain. Physical examination revealed arterial blood pressure difference between the two arms and he was referred to our hospital for further evaluation and treatment. He had a history of peripheral artery disease and he stated that he was on regular clopidogrel and cilostazol treatment. His general condition was good. He was conscious, oriented and cooperative. His vital signs were stable except for blood pressure of $90 / 60 \mathrm{mmHg}$ in the left arm and $130 / 70 \mathrm{mmHg}$ in the right arm. Physical examination revealed poor peripheral pulses in the left arm, but no signs of circulatory disturbances. There were no pathological findings in other system examinations. Electrocardiogram was evaluated as normal sinus rhythm. Laboratory values including cardiac enzymes were within normal limits. Computed tomography aortography (CTA) was performed due to suspected aortic dissection. Although aortic dissection was not detected in CTA, localized thrombus was seen in the proximal part of the left subclavian artery (SCA) (Figure 1, 2, 3). Low molecular weight heparin was administered subcutaneously at a dose of $0.8 \mathrm{mg}$. The patient was consulted to cardiovascular surgery clinic. The findings were evaluated in favor of chronic thrombus. The patient was advised to continue his current clopidogrel therapy and was discharged from the emergency department with the recommendation to cardiovascular surgery outpatient clinic visit.

SCA thrombosis often occurs due to progressive atherosclerosis, vascular damage (including vasculitis) or hypercoagulopathy. It can be seen in two clinical forms: acute and chronic. Chronic SCA thrombosis has been reported to be more common due to turbulent flow caused by angulation at the left SCA outlet (1). In acute form, pain in the arm, coldness, paleness and weakness of peripheral pulses may occur. Some patients in chronic form may describe claudication in the upper extremity after movement,

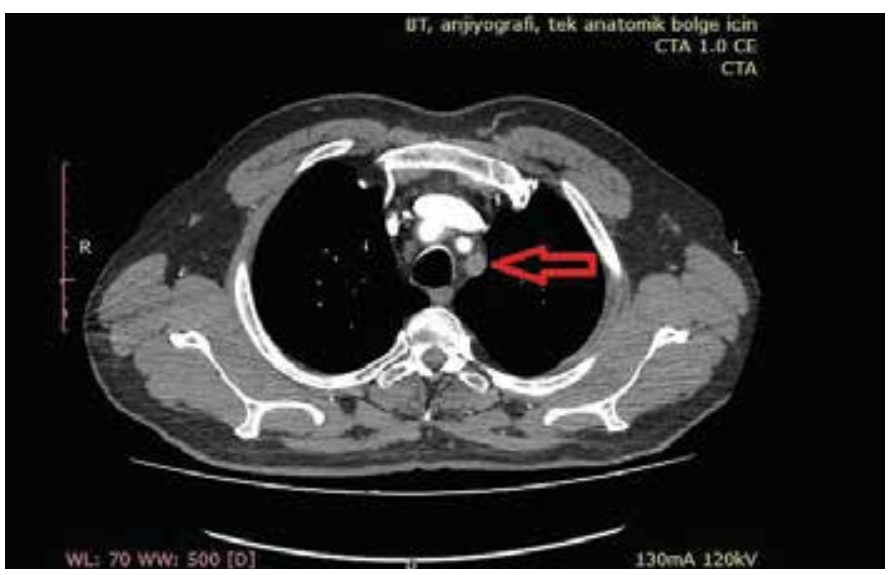

Figure 1. Occlusion of the left subclavian artery

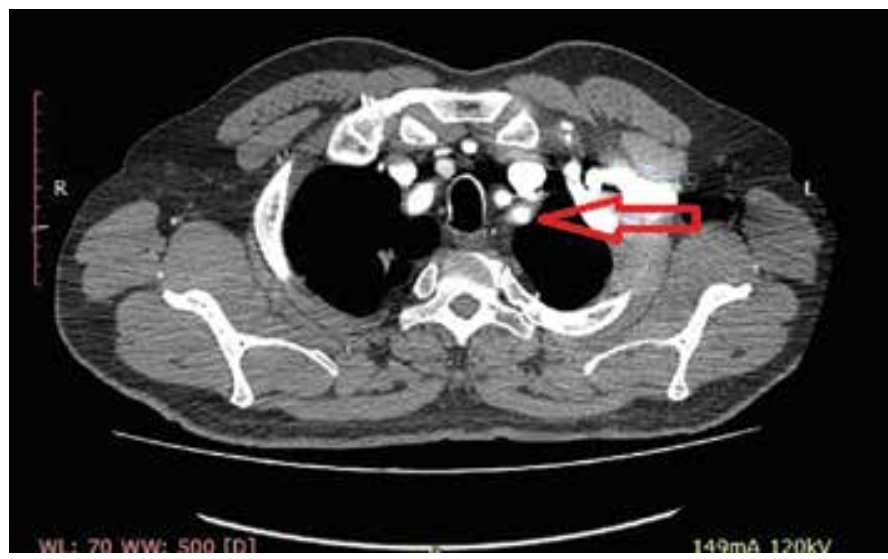

Figure 2. Blood refilling in the distal part of the occlusion

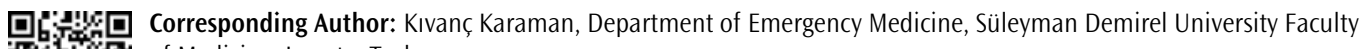
of Medicine, Isparta, Turkey

Phone: +90 5553244227 E-mail: kiwanckaraman@hotmail.com ORCID ID: orcid.org/0000-0002-4105-2785

Received: 30.07 .2019

Cite this article as: Karaman K, Sahin K. An Unusual Diagnosis in a Patient with Chest Pain and Decreased Left Upper Extremity Blood Pressure. Eurasian J Emerg Med. 2019;18(3):169-70.

(C) Copyright 2019 by the Emergency Medicine Physicians' Association of Turkey

Eurasian Journal of Emergency Medicine published by Galenos Publishing House. 


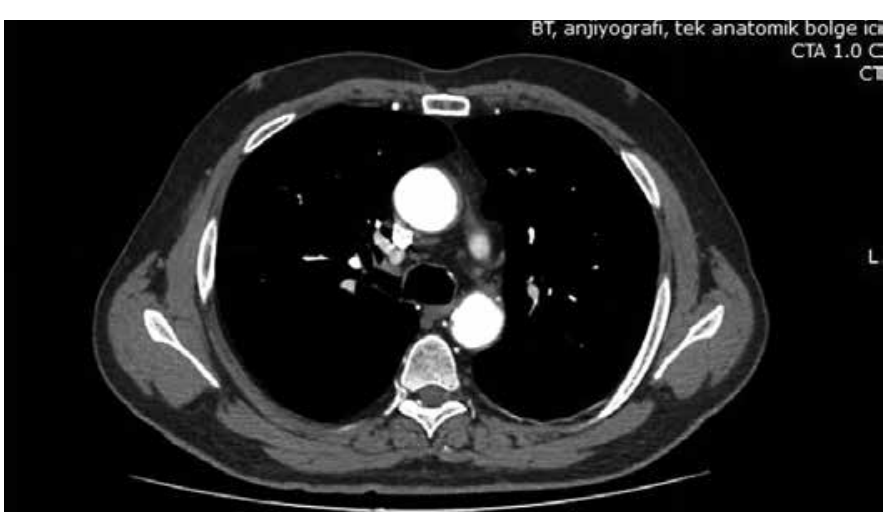

Figure 3. No findings of aortic dissection

but are usually asymptomatic. The distinction between acute and chronic SCA thrombosis is made according to clinical and radiological findings, but there are no definite criteria (2). Emergency thrombolysis or thrombectomy should be performed to prevent limb ischemia in acute form (3). In chronic form, treatment options include surgical interventions.

Emergency physicians initially attempt to rule out aortic dissection in patients with chest pain and pulse difference between extremities. However, SCA thrombosis is an important pathology that should be kept in mind, especially in patients with predisposing factors such as atherosclerosis and vasculitis, and both SCA should be carefully examined after exclusion of aortic pathologies in CTA.
Keywords: Aortic dissection, emergency medicine, subclavian artery occlusion

\section{Ethics}

Informed Consent: Was taken from patient but also any personal information was not mentioned in the text.

Peer-review: Externally peer-reviewed.

\section{Authorship Contributions}

Surgical and Medical Practices: K.S., Concept: K.K., Design: K.K., K.S., Data Collection or Processing: K.K., K.S., Analysis or Interpretation: K.K., K.Ş., Literature Search: K.K., K.S., Writing: K.K., K.S.

Conflict of Interest: No conflict of interest was declared by the authors.

Financial Disclosure: The authors declared that this study received no financial support.

\section{References}

1. Ochoa VM, Yeghiazarians Y. Subclavian artery stenosis: a review for the vascular medicine practitioner. Vasc Med. 2011;16:29-34.

2. Jones CS, Verde F, Johnson PT, Fishman EK. Nontraumatic Subclavian Artery Abnormalities: Spectrum of MDCT Findings. AJR Am J Roentgenol. 2016;207:434-41.

3. Zeller T, Frank U, Bürgelin K, Sinn L, Horn B, Schwarzwälder U, Roskamm H, Neumann FJ. Treatment of acute embolic occlusions of the subclavian and axillary arteries using a rotational thrombectomy device. Vasa 2003;32:1116. 